\title{
Afterdischarge Thresholds and Kindling Rates in Dorsal and Ventral Hippocampus and Dentate Gyrus
}

\author{
RONALD RACINE, PATTY A. ROSE AND W. M. BURNHAM
}

SUMMARY: Electrodes were implanted into dorsal hippocampus (CAl), ventral $C A l$, dorsal dentate gyrus or ventral dentate gyrus. Epileptiform afterdischarge $(A D)$ thresholds were lower in dorsal areas than in ventral areas. Dorsal areas, however, required a greater number of stimulations to develop ("kindle") a fully generalized convulsion than did ventral areas. Thresholds and kindling rates in the dentate gyrus were

RESUMÉ: Des électrodes furent implantées dans l'hippocampe dorsal (CAI), le CAl ventral, les circonvolutions dentelées dorsales et ventrales; les seuils d'après-décharges épileptiques furent trouvés plus bas dans les régions dorsales que ventrales. Cependant les régions dorsales nécessitèrent un plas grand nombre de stimulations pour développer ("Kindling") une convulsion généralisée que les régions ventrales. Lès seuils et taux de "Kindling" de la intermediate between dorsal and ventral $C A 1$, except for the ventral dentate which had higher $A D$ thresholds than ventral CAl.

Secondary sites within the hippocampus subsequently kindled within a few stimulations following completion of kindling in the primary site, regardless of which hippocampal area served as the primary site.

circonvolution dentelée étaient intermédiaires entre les CAl dorsaux et ventraux, sauf en ce qui concerne la région dentelée ventrale qui avait des seuils d'après-décharges plus élevés que ceux du CAl ventral.

Les sites secondaires à l'intérieur de l'hippocampe furent subséquemment induits en deça de quelques stimulations après le "Kindling" du site primaire, peu importe quelle zone de l'hippocampe constitue le site primaire.
From the Department of Psychology, McMaster University, Hamilton, Ontario, and Department of Pharmacology, University of Toronto, Toronto, Ontario.

Reprint requests to: Dr. Ronald Racine, Department of Psychology, McMaster University, Hamilton, Ontario, Canada L8S $4 \mathrm{KI}$.

\section{INTRODUCTION}

Most forebrain and some brainstem structures will respond to direct electrical stimulation with an epileptiform afterdischarge (AD) if the stimulation intensity is high enough. These same areas will respond with increasingly stronger discharges and behavioral (convulsive) responses if the stimulation is spaced in time and repeated (Goddard et al, 1969; Racine, 1972). This change in responsiveness due to repeated stimulation has been named "kindling"' by Goddard. Kindling has been studied most thoroughly in the amygdala and cortex (Goddard et al, 1969; Racine, 1972; Racine, 1975). Other structures, including the hippocampus, have been studied less thoroughly.

Burnham (1975) has recently reported an interesting difference between the kindling response of the dorsal and ventral hippocampus. In his studies, the dorsal hippocampus required a greater number of stimulations than the ventral hippocampus before maximal seizure responses were developed. The following study was designed to confirm and extend Burnham's observations. We have measured dorsal and ventral afterdischarge thresholds, we have tested dentate gyrus as well as hippocampus, and we have measured the effect of kindling of one hippocampal area on the subsequent kindling in other hippocampal areas. It has already been demonstrated by Goddard et al (1969) and Racine (1972) that amygdaloid kindling results in a "savings" effect when secondary sites are subsequently kindled in the same animal. This has been called the "transfer" effect. In the following study we tested for 
transfer between dorsal and ventral areas and between dentate gyrus and hippocampus.

\section{METHOD ,}

Forty-eight male hooded rats (300-380 gms) from Canadian Breeding Farms were used in these experiments. They were divided into four equal groups and then implanted with stimulating/recording electrodes. Each group received a stimulating electrode in a different placement within the hippocampus: dorsal cornu ammonis field 1 (dorsal CA1), ventral cornu ammonis field 1 (ventral CA1), dorsal dentate gyrus and ventral dentate gyrus. An additional hippocampal electrode was implanted into each animal to record intrahippocampal propagation and subsequent "transfer" of kindling between hippocampal sites. The second hippocampal placement was evenly distributed between the other three hippocampal placements used in this experiment. For example, of the 12 rats with stimulating electrodes in dorsal $\mathrm{CA} 1,4$ had an additional electrode in the ventral CA, 4 in the dorsal dentate gyrus, and 4 in the ventral dentate gyrus. All rats were handled for 5 minutes each day for 5 days following surgery. Afterdischarge (AD) thresholds were then determined. One sec of one msec biphasic square wave pulses were appled at a frequency of $60 \mathrm{c} / \mathrm{sec}$. Initial intensity was set as $75 \mu \mathrm{A}$. If an $A D$ was not triggered by this stimulation, the current intensity was doubled and appled 24 hours later. If an $\mathrm{AD}$ was triggered, the intensity was halved the next day. This doubling and halving procedure was continued for 5 days. The lowest current intensity which produced AD was considered as threshold. Any AD's triggered during threshold testing were added to the AD's triggered during subsequent kindling to determine kindling rates.

After AD thresholds had been determined, the kindling procedure was begun. It has been shown that changes in suprathreshold current level have little or no effect on kindling rates (Racine, 1972). Consequently, a standard stimulation intensity of $150 \mu \mathrm{A}$ was applied each day (except in one animal with an AD threshold of $300 \mu \mathrm{A}$ ). Other parameters remained unchanged from threshold testing. These parameters never failed to trigger discharges. Stimulation was continued until two fully generalized convulsions had been triggered. Stimulation was then applied to the other hippocampal electrode until generalized convulsions were again triggered. This provided a measure of the extent of the intrahippocampal "transfer" (Goddard et al, 1969; Racine, 1972). Electrographic responses were recorded throughout the kindling treatment. At the end of the experiment, the brains were removed, sectioned and stained with thionine.

AD durations, AD spike frequency and primary and secondary site AD spike amplitude were measured in all records. The AD spike amplitudes were taken as the mean of a $10 \mathrm{sec}$ block containing the largest amplitude spikes.

\section{RESULTS}

Electrode placements are shown in Figure 1. AD thresholds and kindling rates are shown in Table 1. As can be seen in Table 1, the dorsal placements were significantly different from the ventral placements with respect to kindling rates. The dorsal $\mathrm{CA} l$ and dorsal dentate kindled significantly more slowly than the ventral CAI and ventral dentate. The dorsal placements, however, had significantly lower AD thresholds than the ventral placements (although the ventral CAl vs. dorsal dentate comparison was not significant, all other dorsal-ventral comparisons were significant). The tendency for high thresholds to accompany fast kindling rates was also found within groups and a Spearman's test yielded a correlation of -0.37 between AD threshold and kindling rates $(\mathrm{p}<.05)$.

The changes in $A D$ duration, $A D$ spike amplitude and $A D$ spike frequency are shown in Table II. There

TABLE I

NUMBER OF AD'S TO MAXIMAL CONVULSION

\begin{tabular}{lc|c|c|c} 
& Dorsal CA1 & Dorsal dentate & Ventral Dentate & Ventral CA1 \\
\cline { 2 - 5 } & 51.0 & 44.0 & 31.1 & 27.4 \\
$\mathrm{r}$ & $25-96$ & $24-78$ & $15-60$ & $13-51$
\end{tabular}

$(\mathrm{H}=13.1 ; \mathrm{p}<.01:$ Kruskall Wallis $)$

Dorsal CAl vs. Dorsal dentate $(\mathrm{U}=37$; NS)

* Dorsal CAl vs. Ventral dentate $(U=21 ; p<.05)$

* Dorsal CA1 vs. Ventral CAl $(U=15 ; \mathrm{p}<.01)$

*Dorsal Dentate vs. Ventral Dentate $(U=20 ; p<.05)$

* Dorsal Dentate vs. Ventral CAl $(U=21 ; p<.05)$

Ventral Dentate vs. Ventral CAl $(\mathrm{U}=39$; NS)

AFTER DISCHARGE THRESHOLDS ( $\mu$ Amps)

\begin{tabular}{cc|c|c|c} 
& Dorsal CA 1 & Dorsal dentate & Ventral dentate & Ventral CA1 \\
\cline { 2 - 5 }$\overline{\mathrm{X}}$ & 40.6 & 62.0 & 109.8 & 76.0 \\
$\mathrm{r}$ & $20-112$ & $20-112$ & $28-300$ & $37-130$ \\
\multicolumn{1}{c}{} & \multicolumn{1}{c}{$(\mathrm{H}=12.5 ; \mathrm{p}<.01:$ Kruskall Wallis $)$}
\end{tabular}

Dorsal CAI vs. Dorsal Dentate (U $=33$; NS)

*Dorsal CAl vs. Ventral Dentate $(U=14 ; p<.01)$

* Dorsal CAl vs. Ventral CAl $(\mathrm{U}=19 ; \mathrm{p}<.05)$

* Dorsal Dentate vs. Ventral Dentate $(U=22 ; p<.05)$

* Dorsal Dentate vs. Ventral CAl $(U=40 ; N S)$

Ventral Dentate vs. Ventral CAI (U=37; NS)

*Dorsal-Ventral comparisons are marked with an asterisk. 


\section{DORSAL CA1}

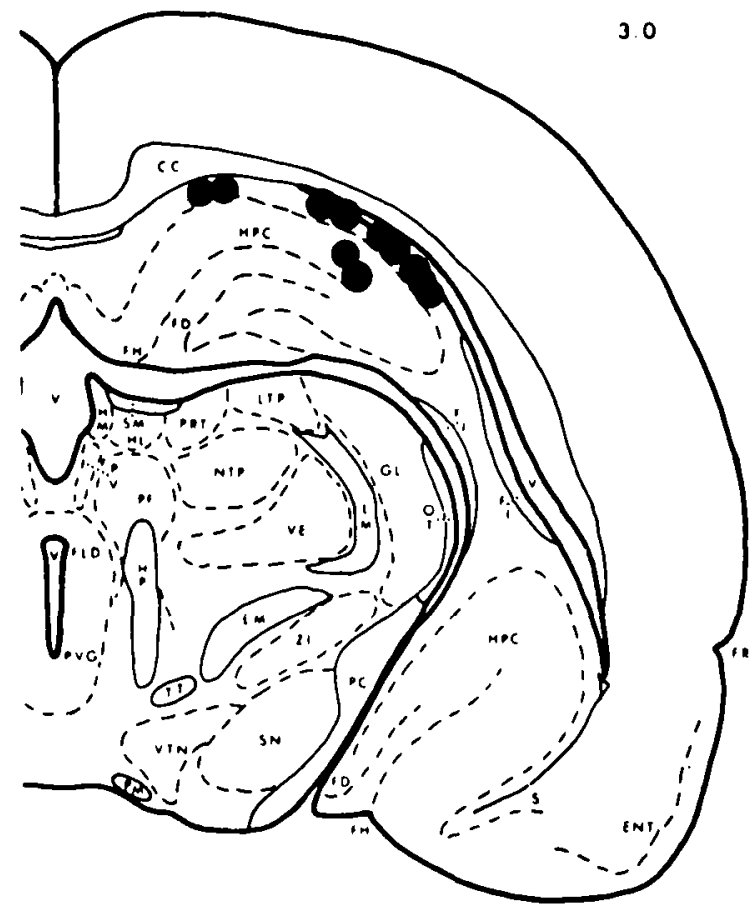

DORSAL DENTATE

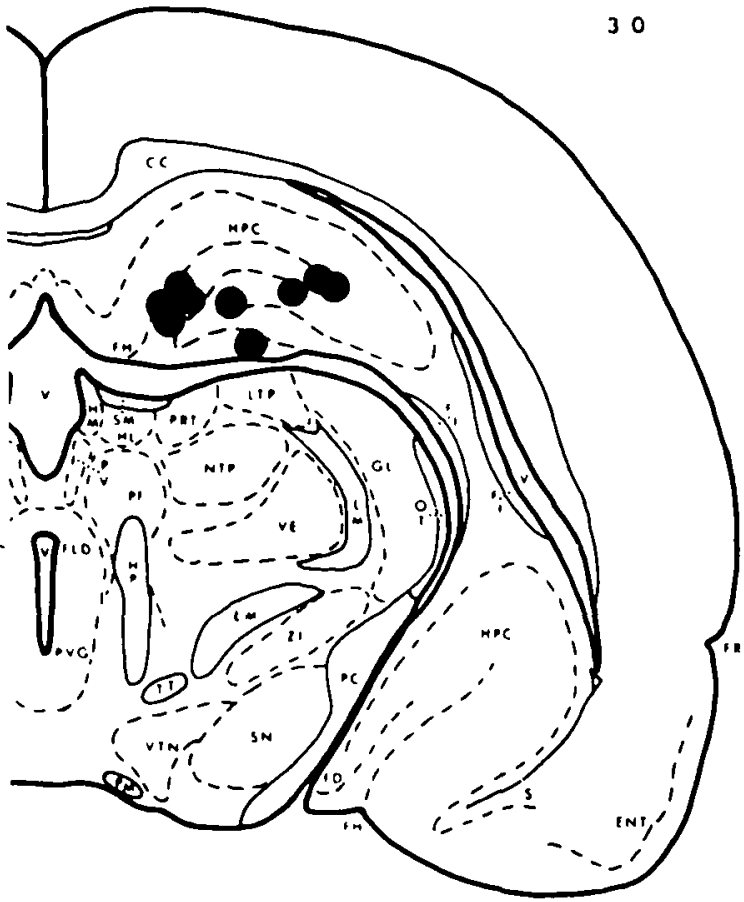

VENTRAL CA1

\section{VENTRAL DENTATE}
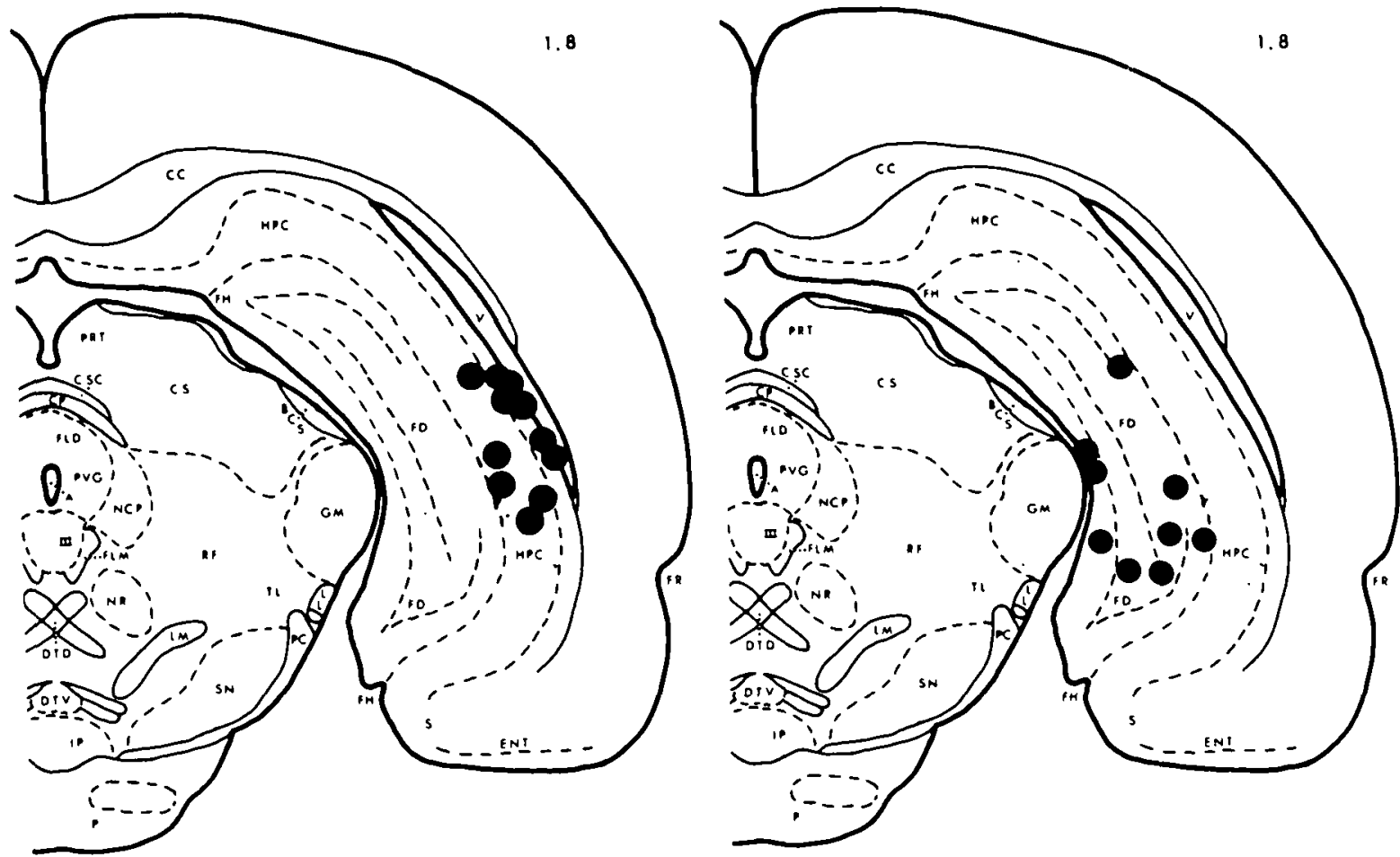

Figure I-Histologically verified placements of electrode tips are shown for the four experimental groups. Atlas diagrams are from Pellegrino and Cushman (1967). 
were no significant differences between the groups on any of these measures before or after the completion of kindling. When all of the animals were grouped together, however, there was a tendency for those subjects showing faster kindling rates to show lower AD spike frequencies and longer AD's on the first day of convulsion.

The increases in $A D$ duration were small in most animals and the AD spike amplitudes showed decreases with kindling in about $40 \%$ of the primary foci. AD spike amplitudes increased in all but 5 of the secondary foci. AD spike frequency increased in all animals over the first few days of kindling and usually reached a stable level long before the appearance of convulsions (Figure 2).

The hippocampal $A D$, regardless of stimulation site, showed an initial duration of 20 to $30 \mathrm{sec}$ followed by a very flat EEG, then by a secondary discharge lasting 10-20 sec and then by a recovery of the EEG (Figure 2). After a number of kindling stimulations had been applied, low frequency $(3-10 / \mathrm{min})$ postictal spiking appeared and continued in some cases until the next stimulation was applied 24 hours later. In all animals, the post discharge recovery of normal EEG was prolonged after kindling was completed (Figure 2). The hippocampal AD's did not usually appear until 2-4 sec after the offset of stimulation. The activity during this period appeared either normal (generally "theta") or flattened. This activity was always seen in the record from the second electrode (Figure 2) and was occasionally seen in the record from the stimulated electrode if the amplifier blocking recovered in time. In a few animals the kindled ronvulsion began immediately even though the recorded discharge had not begun.

The first behavioral responses to accompany the AD's were "wet dog" shakes. All but one of the subjects showing "wet dog" shakes had dorsal placements. Fifty percent of the dorsal hippocampal animals and 7 of the 9 dorsal dentate animals had "wet dog" shakes during the discharges. This response is rarely seen in animals kindled in other sites. A smaller number of animals (6) showed an evoked biting response for several minutes following the discharge. If a glove was slowly advanced towards the animal from the front, it would lunge at the glove, bite it and not let go. There was no vocalization or threat preceding the attack and little movement after the bite. During this period the animal would also bite a gloved hand if picked up. These animals showed this biting response after every discharge but never at any other time. We have never seen this response in animals stimulated in the amygdala, cortex or brainstem.

The convulsions showed two basic types and patterns of development. Many of the animals de-
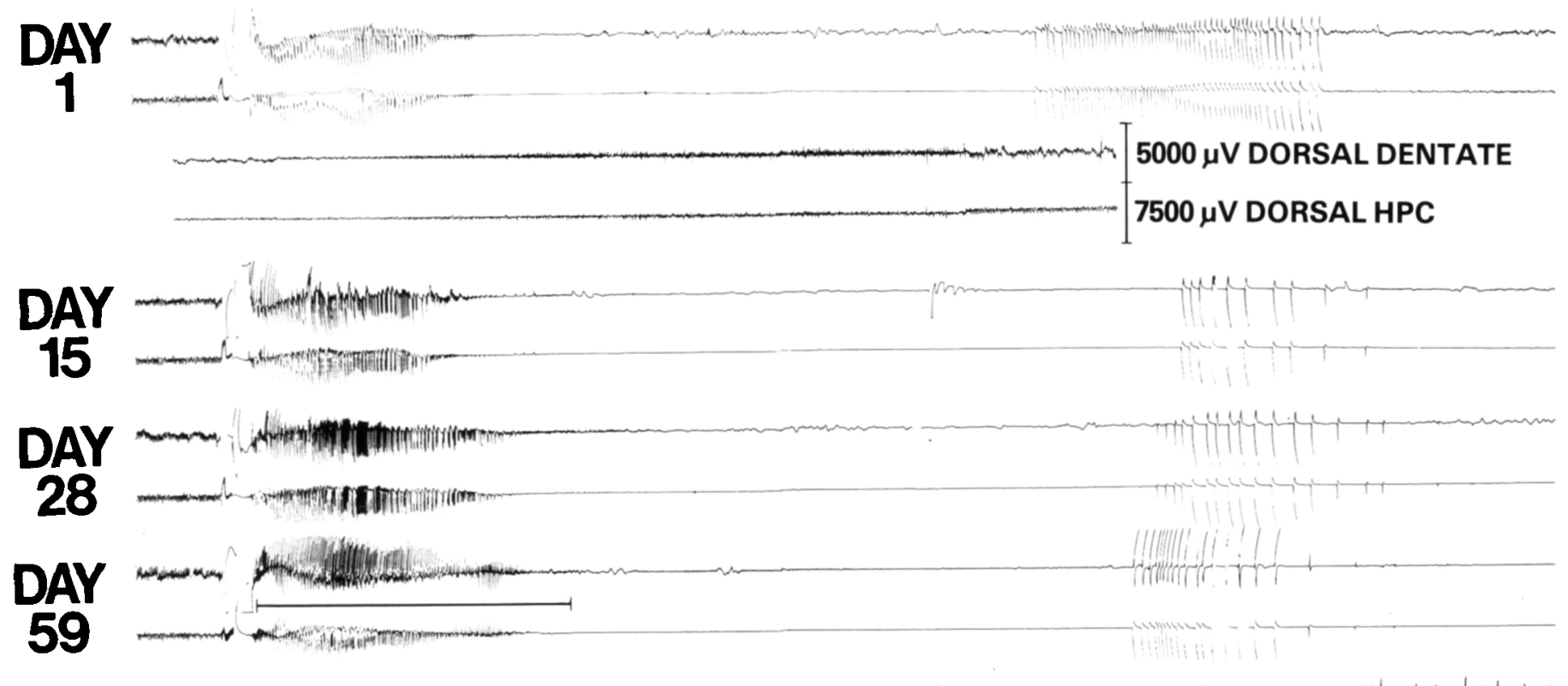

Figure 2-Development of epileptiform afterdischarge (AD) evoked by electrical stimulation of the dorsal dentate gyrus (upper trace). Seven sec of prestimulation EEG is included with each trace, and the switching artifact indicates the onset of a 1 sec train of stimulation. The ipsilateral dorsal hippocampus (CAI) record (lower trace) is also included. The Ist, 15th, 28th, and 59th AD's are shown. The first maximal convulsion occurred on day 59 and lasted for $30 \mathrm{sec}$ (as indicated by line). Note that the AD spike frequency increases as does the post $\mathrm{AD}$ recovery time (compare Day 1 and Day 59 traces). 
TABLE II

AD DURATIONS (SEC.)

\begin{tabular}{|c|c|c|c|c|c|c|c|c|}
\hline & \multicolumn{2}{|c|}{ Dorsal CAl } & \multicolumn{2}{|c|}{ Dorsal dentate } & \multicolumn{2}{|c|}{ Ventral dentate } & \multicolumn{2}{|c|}{ Ventral CA1 } \\
\hline & Initial & Final & Initial & Final & Initial & Final & Initial & Final \\
\hline$\overline{\mathrm{X}}$ & 20.1 & 25.3 & 21.2 & 35.7 & 23.3 & 37.1 & 28.3 & 35.7 \\
\hline$r$ & $12-30$ & $15-40$ & $15-30$ & $17 \cdot 90$ & $15-30$ & $20-90$ & $20-60$ & $22-70$ \\
\hline
\end{tabular}

AD SPIKE FREQUENCY (SPIKE/SEC.)

\begin{tabular}{|c|c|c|c|c|c|c|c|}
\hline \multicolumn{2}{|c|}{ Dorsal CA1 } & \multicolumn{2}{|c|}{ Dorsal dentate } & \multicolumn{2}{|c|}{ Ventral dentate } & \multicolumn{2}{|c|}{ Ventral CAl } \\
\hline Initial & Final & Initial & Final & Initial & Final & Initial & Final \\
\hline 3.9 & 8.5 & 4.3 & 8.6 & 4.7 & 7.8 & 4.0 & 7.8 \\
\hline $3-5$ & $4-12$ & $3-7$ & $4-11$ & $3-10$ & $4-12$ & $3-5$ & $4-12$ \\
\hline
\end{tabular}

PRIMARY FOCUS AD SPIKE AMPLITUDES $(\mu \mathrm{V})$

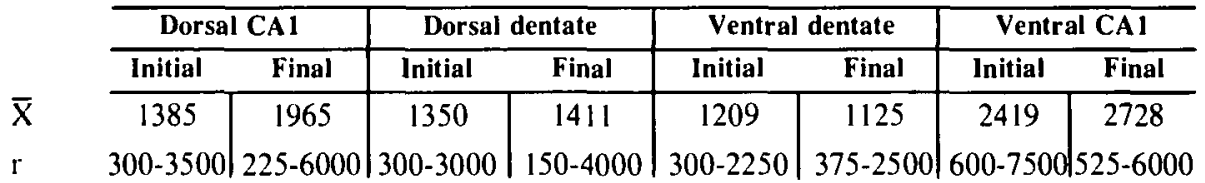

SECONDARY FOCUS* AD SPIKE AMPLITUDES $(\mu \mathrm{V})$

\begin{tabular}{|c|c|c|c|c|c|c|c|c|}
\hline \multirow{2}{*}{$\begin{array}{l}\text { Stimu- } \\
\text { lated } \\
\text { site: }\end{array}$} & \multicolumn{2}{|c|}{ Dorsal CAl } & \multicolumn{2}{|c|}{ Dorsal dentate } & \multicolumn{2}{|c|}{ Ventral dentate } & \multicolumn{2}{|c|}{ Ventral CAI } \\
\hline & Initial & Final & Initial & Final & Initial & Final & Initial & Final \\
\hline $\bar{X}$ & 1127 & 1355 & 1072 & 1469 & 531 & 966 & 1631 & 1500 \\
\hline$r$ & $200-4000$ & $300-2625$ & $100-4500$ & $350-3750$ & $75-1250$ & $150-2100$ & $300-5250$ & $300-4000$ \\
\hline
\end{tabular}

* Listed according to structure stimulated (primary focus).

veloped convulsions in much the same way as animals stimulated in the amygdala (Racine, 1972). The fully generalized convulsion developed over a $3-4$ day period with the first response involving mouth and head movements. The head movements were followed by forelimb clonus, then by rearing and, finally, rearing and falling. Many of the animals, however, showed seizure responses that resembled those evoked by anterior neocortical stimulation (Racine, 1975). These subjects showed a tendency to become prostrate immediately. This loss of postural control was accompanied by forelimb clonus and mild opisthotonus. About $20 \%$ of the animals showed the maximal seizure response quite suddenly with little or no prior indication that the convulsive response was developing. Most of these animals showed a prostrate response or a combination of rearing and prostrate-type convulsive re- sponses. There was a tendency, though not significant, for the prostrate seizures to appear more frequently in subjects with slow kindling rates.

The subjects showing the prostrate type seizure responses often appeared ataxic and "semiconscious" for several minutes following the discharge. They would, for example, walk off the end of the table, which they would never do in the normal state. This is also characteristic of the anterior neocortex kindled response.

The convulsive response often appeared during the flattened period in the EEG between the first and second discharges. It has been reported previously (Racine, 1972) that other structures (e.g. the amygdala or cingulate cortex) often show their maximal amplitude spikes during this flattened hippocampal EEG. Some of the animals in this experiment showed large amplitude spik- ing in the other hippocampal site while the primary focus EEG was flattened. These spikes, however, rarely appeared to be as large (relative to background EEG) as those found in other structures in previous experiments.

Surprisingly, the intrahippocampal secondary sites all kindled equally rapidly regardless of which area served as the "transfer" or secondary site. When the stimulation was switched to the second hippocampal placement after completion of kindling at the primary site, it was found that all secondary sites kindled within five days of stimulation $(\bar{x}=1.5$ days).

\section{DISCUSSION}

The main findings presented in this paper are that dorsal hippocampal AD thresholds are lower than ventral hippocampal $A D$ thresholds, but the dorsal hippocampus requires a greater number of stimulations to develop convulsions. The dorsal and ventral hippocampus differ in a number of ways. They are different functionally according to Siegal and Flynn (1968), Nadel (1968), Steven and Cowey (1973) and others. Nadel (1968), for example, reported that dorsal hippocampal lesions retarded acquisition of one-way active avoidance response, while ventral lesions tended to facilitate acquisition on the same task. Projections to and from the dorsal and ventral hippocampus also differ according to Niemer et al (1963), Adey et al (1957), Siegel and Tassoni (1971a, b) and Elul (1967a, b). This difference in projections probably accounts, in part, for the difference in kindling rates. The amygdala and anterior pryiform cortex are known to show the fastest kindling rates and both Elul (1967) and Siegel and Tassoni (1971a) claim that the ventral hippocampus has stronger connections with the anterior pyriform cortex. This would also agree with Goddard's proposal that kindling rates for subcortical structures are related to the degree of connection with the amygdala (Goddard et al, 1969). There are, of course, other possibilities. The dorsal and ventral hippocampus may differ in the ex- 
tent to which they activate brainstem sites that are critical for driving motor seizure responses. We are currently attempting to determine the relative strengths of "coupling" between various forebrain sites and various brainstem sites before, during and after kindling.

It is less clear why the AD thresholds should differ between dorsal and ventral hippocampus, and it is not clear why there should be a negative correlation between kindling rates and $\mathrm{AD}$ threshold. This negative correlation, however, is not unique to the hippocampus; we have seen it in the amygdala as well, within the same strain (unpublished observations), and it has been reported in the amygdala when two rat strains were compared (Zaide, 1973). Tryon "bright" rats had low AD thresholds and slow kindling rates in the amygdala compared to Tryon "dull" rats Rats (Zaide, 1973).

It is interesting that the hippocampal $A D$ does not appear until 2-4 sec after the stimulation has been applied (at least in the record from the second electrode). In an earlier study (Newberry et al, 1975) it was found that the post-ictal spikes could be triggered by single square wave pulses applied to the hippocampus of a kindled animal. Again, these spikes followed the stimulation by
2-4 sec. Intracellular recordings during this $2-4 \mathrm{sec}$ period might provide some information about the mechanisms for the triggering of AD.

\section{REFERENCES}

ADEY, W., SUNDERLAND, S. and DUNLOP, C. (1957). The entorhinal area: electrophysiological studies of its interrelations with rhinencelphalic structures and the brainstem. Electroencephalography and Clinical Neurophysiology, 9, 309-324.

BURNHAM, W. (1975). Primary and "transfer" seizure development in the kindled rat. Canadian Jounal of Neurological Science, 2, 417-428.

ELUL, R. (1964). Regional differences in the hippocampus of the cat. I. Specific discharge patterns of the dorsal and ventral hippocampus and their roles in generalized seizures. Electroencephalography and Clinical Neurophysiology, 16, 470-488.

ELUL, R. (1964). Regional differences in the hippocampus of the cat. II. Projections of the dorsal and ventral hippocampus. Electroencephalography and Clinical Neurophsiology, 16, 489.502.

GODDARD, G., McINTYRE, D., LEECH, C. (1969). A permanent change in brain function resulting from daily electrical stimulation. Experimental Neurology, 25, 295-330.

NADEL, L. (1968). Dorsal and ventral hippocampal lesions and behavior. Physiology and Behavior, 3, 891-900.

NEIMER, W., GOODFELLOW, E., SPEAKER, J. (1963). Neocortical relations in the cat. Electroencephalography and Clinical Neurophysiology, 15, 827-838.

NEWBERRY, F., RACINE, R., SMITH, G. K. (1975). Potentials evoked by stimulation of the hippocampus: low frequency suppression effect. Physiology and Behavior, 15. 551-559.

PELLEGRINO, L, CUSHMAN. A. A stereotaxic atlas of the rat brain. $196 \%$ Meredith, New York.

RACINE, R. (1972). Modification of seizure activity by electrical stimulation. Il, Motor seizure. Electroencephalography and Clinical Neurophysiology, 32, 281-294.

RACINE, R., BURNHAM, W., GARTNER, J. (1973). First trial motor seizures triggered by amygdaloid stimulation in the rat. Electroencephalography and Clinical Neurophysiology, 35, 487-494.

RACINE, R. (1975). Modification of seizure activity by electrical stimulation: cortical areas. Electroencephalography and clinical Neurophysiology, 38, 1-12.

SIEGEL, A., FLYNN, F. (1968). Differential effects of electrical stimulation and lesions of the hippocampus and adjacent regions upon attack behaviour in cats. Brain Research, 7, 252-267.

SIEGEL, A., TASSONI, J. (1971a). Differential projections from the ventral and dorsal hippocampus of the cat. Brain, Behavior and Evolution, 4, 185-200.

SIEGEL, A., TASSONI, J. (197lb). Differential efferent projections of the lateral and medial spetal nuclei to the hippocampus in the cat. Brain, Behavior and Evolution, 4, 201-219.

STEVENS, R., COWEY, A. (1973). Effects of dorsal and ventral hippocampal lesions on spontaneous alternation, learned attention and probability learning in rats. Brain research, 52, 203-224.

ZAIDE, J. (1974). Differences between Tryon bright and dull rats in seizure activity evoked by amygdala stimulation. Physiology and Behavior, 12, 527-534. 